\title{
Treatment of anterior vaginal wall prolapse with and without polypropylene mesh: a prospective, randomized and controlled trial - Part I
}

José Tadeu Nunes Tamanini, Mirce Milhomem da Mota Tamanini, Renata Cristina de Oliveira Souza Castro, Paulo Cezar Feldner Jr, Rodrigo de Aquino Castro, Marair Gracio Ferreira Sartori, Manoel João Batista Castello Girão

Department of Medicine, Federal University of Sao Carlos (JTNT), Sao Carlos; Ambulatory of Urogynecology, Health Secretary of Jau (MMMT, RCOSC), Jau; Department of Urogynecology and Pelvic Surgery, Department of Gynecology (PCFJr, RAC, MGFS, MJBCG), Federal University of Sao Paulo, Sao Paulo, SP, Brazil

\section{ABSTRACT}

Objective: To compare the use of polypropylene mesh (PM) and the traditional anterior vaginal wall colporraphy in women with anterior vaginal wall prolapse (AVWP) using objective and subjective tests and evaluation of quality of life (QoL).

Materials and Methods: One hundred women were randomly distributed in two preoperatory groups. The first group (mesh) $(n=45)$ received a PM implant and the control group ( $n=55$ ) was submitted to traditional colporraphy. Postoperatory follow-up was done after 12 months. The primary objective was the correction of the Ba point $\leq-2$ POP-Q (Pelvic Organ Prolapse Quantification System) and the secondary objective was the improvement of vaginal symptoms and QoL through ICIQ-VS (International Consultation on Incontinence Questionnaire - Vaginal Symptoms). Complications related to the use of PM or not were also described.

Results: There was a significant difference between all POP-Q measures of pre- and postoperatory periods of each group in particular. There was a significant difference of the Ba point of the postoperatory period between the Mesh and Control group. The mean of Ba point in the Mesh group was statistically lower than of the Control group, depicting the better anatomical result of the first group. Both techniques improved vaginal symptoms and QoL. The most frequent complication of the Mesh group was prepubic hematoma in the perioperative period. In 9.3\% of the cases treated with mesh it was observed PM exposition at the anterior vaginal wall after 12 months, being most of them treated clinically.

Conclusion: The treatment of AVWP significantly improved the Ba point in the Mesh group in comparison to the Control group. There were no differences of the vaginal symptoms and QoL between the two groups after 12 months. There were few and low grade complications on both groups.

\section{ARTICLE INFO}

\section{Key words:}

Prolapse; Therapeutics; Quality of Life; Pelvic Floor

Disorders

Int Braz J Urol. 2013; 39: 519-30

Submitted for publication: December 21, 2012

\section{Accepted after revision:}

June 07, 2013

\section{INTRODUCTION}

There are many published studies in the literature on association of the aging process and prevalence of female pelvic floor diseases, such as genital prolapses and urinary incontinence. Pelvic organ prolapses (POP) are prevalent conditions and affect $30 \%$ of childbearing women (1-4). The 
causes of POP are not clear, but normal delivery seems to be the primary etiologic factor. In the Brazilian population, the independent risk factors for POP are vaginal delivery, a large fetus and family history of POP (5).

Many surgical techniques have been proposed to correct POP. However, the published results are not completely satisfactory or homogeneous. For example, the success rates of traditional anterior colporraphy to correct anterior vaginal wall prolapse vary from 37 to $100 \%$ (6).

The present study was proposed to evaluate women with AVWP treated with anterior traditional colporraphy using PM or not, with objective and subjective tests and QoL impact.

\section{MATERIALS AND METHODS}

\section{Study Design and Objectives}

This is a prospective, randomized, single-blinded and controlled study to evaluate the outcomes of two surgical procedures to correct AVWP. Urinary symptoms such as urgency and stress urinary incontinence (SUI) will be addressed in another study (Part II).

\section{Patients, study location and eligibility criteria}

From February 2008 to December 2010, 122 women attending the Ambulatory of Urogynecology, Health Secretary of Jau, SP, Brazil, were selected. Women 45 years old or older, with AVWP $\geq$ II (POP-Q Stage) (7) without previous surgical correction or with previous surgical treatment of AVWP without the use of PM were selected. The criteria of exclusion or included: women who were previously treated (due to AVWP or SUI) using PM, who were receiving oncological treatment, with altered Papanicolau Smear exam or with uterine bleeding, with genital or acute urinary infection, patients who didn't commit to ambulatory follow-up or that refused the written informed consent.

\section{Diagnosis and data collection}

Methods, definitions and units were used according to the standards of the International Continence Society (ICS) and International Urogynecology Association (IUGA) (8). Data included age (years), parity, number of deliveries, body mass index (BMI - Kg/m2), hormonal status (pre-, peri and postmenopausal), history of previous histerectomy (yes or no) and POP stage (POP-Q). Clinical categories were used to evaluate the hormonal status. Women with more than 12 months of amenorrhea were considered in the postmenopausal period. The study was approved by the Ethical Committee of the Federal University of Sao Paulo under the number 1335/08.

The same group of authors idealized, developed and conducted all steps of the study, including follow-up. PM supplies did not donate funds or surgical devices samples for the study.

\section{Evaluations}

\section{Objective:}

POP-Q was used to measure (centimeters) the supporter of several anatomical aspects of the vaginal canal (7);

\section{Subjective:}

ICIQ-VS: This is a translated and validated questionnaire for Portuguese (9) used to evaluate several pelvic floor dysfunctions including questions regarding intestinal, vaginal, sexual symptoms and QoL impact. It includes 14 questions divided into three independent domains. Vaginal symptoms score (VSS) varies from 0 to 53. Sexual symptoms score (SSS) varies from 0 to 58 and QoL impact score varies from 0 to 10 . Usually each question has 3 to 5 possible answers; the higher the score, the most severe is the symptom or the negative QoL impact.

Safety evaluation related to the use (or not) of PM implant

The specific complications related to the PM implant were described and standardized by ICS/ IUGA in order to define adequately the status of the disease caused by the complication of its use (10).

\section{Objectives}

Primary - POP evaluation using Ba Point $\leq$ -2 (POP-Q) and POP-Q stages ( 0 and 1 ) after 12-month follow-up.

Secondary - vaginal symptoms and QoL impact evaluation using the ICIQ-VS scores (VSS and 
QoL) and surgical complication by means the ICS/ IUGA international code after 12-month follow-up.

Polypropylene mesh kit description

NAZCA TC KIT (Promedon, Cordoba, Argentina)

NAZCA TC kit includes type 1 PM, monofilament, with macropores varying from 0.5 to $1 \mathrm{~mm}$ diameter and density of $60.5 \mathrm{~g} / \mathrm{m} 2$. PM body contains $6 \mathrm{~mm}$ diameter holes in order to facilitate integration with host tissue, lowering the amount of synthetic implanted material and local inflammatory reaction. Four self-adjustable tapes of the same material arise from the body, ending in needle connectors. Two of these tapes are passed through prepubic insertion of the needles (vaginal suprapubic route) and the other two (posterior) are passed by the needles through transobturator route. The needles reach the tendineous arcs, close to the ischial spines bilaterally (11).

\section{Surgical procedure}

All surgeries were performed under spinal anesthesia and all patients received $2 \mathrm{~g}$ of IV cephazolin for prophylaxis. Bladder catheter was inserted in the beginning of the surgery and removed in the first postoperatory day. As needed, concurrent procedures were performed, such as posterior colporraphy and vaginal hysterectomy. Patients of the control group with urodynamic diagnosis of SUI were concurrently treated with retropubic synthetic sling. All patients were operated by the same surgical team (JTNT, MMMT). Before the beginning of the study, the surgeons performed two surgeries using polypropylene mesh kit in order to reduce the learning curve impact on the final results.

\section{NAZCA TC surgical procedure}

With the patient in the lithotomy position, a midline incision in the anterior vaginal wall is performed, from the midurethra to the uterine cervix. The dissection is continued until the ischial-pubic branch and inferior edge of the pubic symphysis. The needles are passed from the vaginal incision to the suprapubic region in order to allocate the prepubic tapes. After removing the handle of the needle on the vaginal side, it is reconnected on the suprapubic side of the needle. After the anterior tape of the NAZCA TC is connected, the needle is gently pulled and the maneuver is finished with the exteriorization of the anterior tape in the suprapubic region. The same maneuver is made in the other side, creating a bracket of the median urethra. The transobturator needle is passed through the genitofemoral fold $2 \mathrm{~cm}$ laterally and $3 \mathrm{~cm}$ inferiorly to the urethral meatus. This needle must reach the region close to the ischial spine, exteriorized through the vaginal incision. The posterior tapes are connected to the needle and removed, exteriorizing through the genitofemoral fold incision. This maneuver is repeated in the contralateral side. The body of the mesh is fixed with absorbable sutures in the region of the cardinal ligaments and in the region of the cervical ring. The four tapes are adjusted in order to correct AVWP without folds or material redundancy. The excess is discharged before the closure of the anterior vaginal wall incision, performed with separated sutures of Vycril 2-0 (11).

\section{Traditional anterior colporraphy}

With the patient in the lithotomy position, a midline incision on the anterior vaginal wall is performed, from the midurethra to the uterine cervix. The anterior vaginal wall is separated from the vesicovaginal fascia and from the bladder using pointless detachment. This maneuver identifies occasional lesion (relaxation or rupture) of the vesicovaginal fascia. In case of central defect it is corrected using plication of the fascia along the midline using separated sutures of Vycril 2-0. Lateral defects are treated using localized sutures with Vycril 2-0 (12).

\section{Statistical analysis}

In order to evaluate preoperatory differences between both groups, chi-square test was used for cathegoric variables and t-Student test for continuous variables with normal distribution. All numerical data were expressed as mean \pm standard deviation (SD). Paired t-test was used to detect differences between pre- and postoperatory periods. The significance level adopted was 5\%.

\section{Sample size calculation}

The sample size was estimated upon literature data $(6,12)$. It was expected anatomical failure after 12-month follow-up of 38\% for control group and $12 \%$ for mesh group. In order to detect this difference (bilateral test), with 0.05 level of significan- 
ce and power of the test $80 \%, 42$ women should be allocated at least in each group. With an estimate of 10\% loss after 12-month follow-up, a total of 92 women were randomized. The sample was increased to 100 women in order to consider a $20 \%$ loss of follow-up after 24 months.

\section{Randomization and blinding}

This trial adopted single-blind masking to reduce bias derived from the knowledge of the patients about which procedure she was submitted.

Randomization based in a single sequence of random tasks is called simple randomization. This technique maintains complete randomization of a single subject in a determined group, with adequate balance, mainly in groups with more than 100 individuals (13). Randomization was made by simple raffle few minutes before surgery when the result was informed to the surgical team, in order to proceed with the designed surgery.

Women were randomly distributed in two groups: Mesh group $(\mathrm{M})(\mathrm{n}=45)$ that used PM implant and Control group (C) $(n=55)$, treated with traditional anterior colporraphy.

Figure-1 shows details of patient selection, including randomization and the final number of evaluated patients after 12-month follow-up in both groups.

Figure 1 - Patient flow chart, randomization and group allocation.

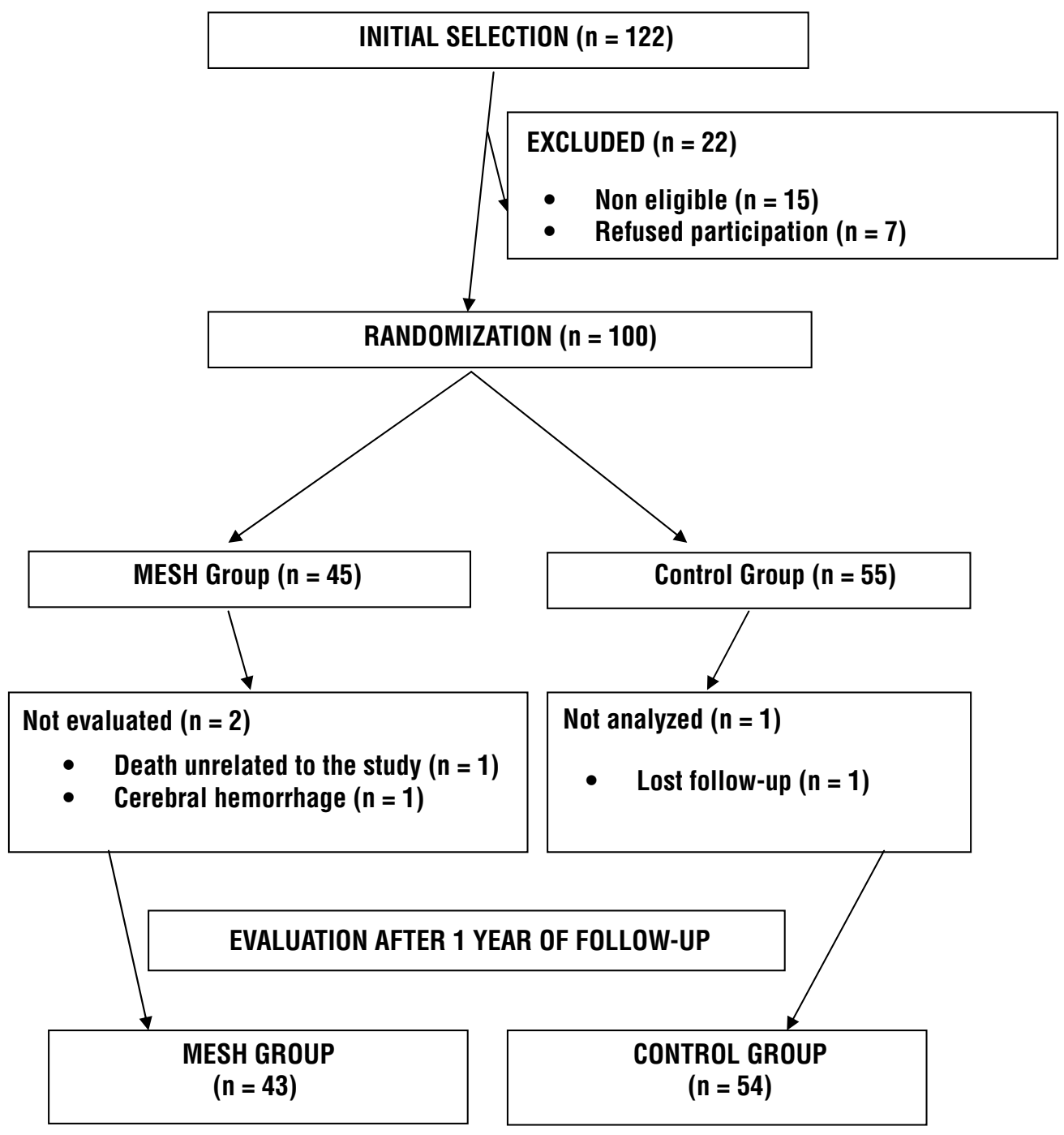


Concurrent surgeries were performed according patient's individual needs. Postoperatory evaluation was performed after 12 months of surgery. The informed consent was read and signed by all patients before the beginning of the study.

\section{RESULTS}

During the preoperatory period, both groups were homogeneous regarding age, parity, number of deliveries, BMI, hormonal status, previous hysterectomy and POP stage, indicating an adequate randomization effect (Table-1). Table-2 shows the pre- and postoperatory POP-Q measures. Both groups were also homogeneous according to these variables, since there was no significant statistical difference of all POP-Q measures between groups in the preoperatory period. There was a statistical significant difference in all POP-Q values between the pre- and postoperatory period in each particular group, demonstrating that both techniques were able to improve anatomical parameters. However, according to the established cure criteria (Ba Point $\leq-2$ ) there was a statistical significant difference of $\mathrm{Aa}$ and $\mathrm{Bb}$ measures (POP-Q) in the postoperatory period between groups Control and Mesh. Bb means in the preoperatory period were +3.38 in Mesh group and +2.55 in Control group $(p=0.10)$. Measures for the same point at the postoperatory period were -2.46 for Mesh group and -1.57 for Control group ( $\mathrm{p}<0.0001)$ (Table-2). According to the POP-Q stage classification, 36/43 (83.7\%) patients of Mesh group and 30/53 (55.5\%) patients of Control group were considered cured (Stages 0 and I) after 12-month follow-up and this difference was considered statistically significant $(p=0.006)(T a-$ ble-3). Absolute risk reduction (ARR) was $28 \%$ and the number needed to treat (NNT) was 4. In regard to the subjective data, there was no difference between groups during preoperatory period for VSS and QoL impact. Due to the low sexual activity in both groups Sexual Symptoms Score (SSS) was not calculated. However, we observed that both surgical procedures improved VSS and QoL impact (Table-4). Table- 5 shows the concurrent surgical procedures in both groups. They were homogeneous in relation to this variable, and there was no significant statistical difference between groups. Table- 6 shows the safety profile of the procedures through analysis of complications during the intra, peri- and postoperatory periods after 12 months.

\section{DISCUSSION}

According to recent published data, the use of PM for correction of POP is controversial. It has been described outcomes of different available meshes in the market, presented as kits $(6,11)$ or in a standard size and molded according to surgeon's preference during surgery $(12,14)$.

Polypropylene mesh to correct POP was first described in 1998 (15) and, since then, its use became popular (16). Recently the Food and Drug Administration (FDA) evaluated the efficacy and safety of the use of PM in POP corrective surgeries in a systematic review study from 1996 to 2011. It was observed that the use of PM to correct AVWP reduces the risk of POP recurrence. However, this anatomical improvement could not be related to better functional results or improvement on QoL (17).

In general, results from our study are in accordance to this systematic review. The Mesh group showed better anatomical improvement of AVWP in relation to the Control group. Differently to the referred review, we have observed that both groups showed a significant improvement of the vaginal symptoms and QoL impact, what is in accordance to the results presented by Palma et al. These authors evaluated 104 women treated with NAZCA TC in an international multicentric study (11). Another trial with similar outcomes was published by Nguyen and Burchette (18). They studied 76 patients with AVWP treated by anterior colporraphy with or without use of PM in a randomized controlled study. It was observed success rate of 55\% of the anterior colporraphy group versus $87 \%$ of the mesh group, but both groups showed improvement of urinary and POP symptoms. Delroy et al. (19) in a prospective, controlled and randomized trial treated women with AVWP using the same kit of the present study and showed an anatomical success (Point $\mathrm{Ba}<$ -1) in 82.5\% in group Mesh and 56.4\% in Control group at 12-month follow-up. The NNT was 4. In both groups it was observed improvement of POP symptoms and QoL impact. Most data presented in 
Table 1 - Demographic characteristics of the Mesh and Control groups during preoperatory period $(n=100)$

\begin{tabular}{|c|c|c|c|}
\hline Demographic characteristics & $\begin{array}{l}\text { Mesh } \\
(n=45)\end{array}$ & $\begin{array}{l}\text { Control } \\
(n=55)\end{array}$ & $p$-value \\
\hline \multicolumn{4}{|l|}{ Age (years) } \\
\hline Mean (SP) & $66.8(9.2)$ & $63.4(9.5)$ & $0.08^{*}$ \\
\hline Interval (min/max) & $53-84$ & $48-84$ & \\
\hline \multicolumn{4}{|l|}{ Parity } \\
\hline Nulliparous n (\%) & $0(0)$ & $3(5.5)$ & $0.94^{*}$ \\
\hline Multiparous n (\%) & $45(100)$ & $52(94.5)$ & \\
\hline \multicolumn{4}{|l|}{ Number of deliveries } \\
\hline Mean (SD) & $4.2(2.6)$ & $4.2(2.7)$ & $0.94^{*}$ \\
\hline Interval (min/max) & $1-14$ & $0-12$ & \\
\hline \multicolumn{4}{|l|}{ BMI $\left(\mathrm{kg} / \mathrm{m}^{2}\right)$} \\
\hline Mean (SD) & $27.5(5.4)$ & $27.8(4.9)$ & $0.76^{*}$ \\
\hline Interval (min/max) & $17-42$ & $16-39$ & \\
\hline \multicolumn{4}{|l|}{ Hormonal status } \\
\hline Pre-menopausal (\%) & $2(4.4)$ & $0(0)$ & $0.86^{\star *}$ \\
\hline Per-menopausal (\%) & $0(0)$ & $1(0.2)$ & \\
\hline Post-menopausal (\%) & $43(95.6)$ & $54(99.8)$ & \\
\hline \multicolumn{4}{|l|}{ Previous hysterectomy } \\
\hline Yes $(\%)$ & $3(6.7)$ & $6(10.9)$ & $0.41^{\star *}$ \\
\hline No $(\%)$ & $42(93.3)$ & $49(89.1)$ & \\
\hline \multicolumn{4}{|l|}{ POP stage (POP-Q) } \\
\hline II (\%) & $10(22.2)$ & $19(34.5)$ & $0.32^{* *}$ \\
\hline III (\%) & $28(62.2)$ & $31(56.4)$ & \\
\hline IV (\%) & $7(15.6)$ & $5(9.1)$ & \\
\hline
\end{tabular}

Values showed as mean \pm standard deviation (SD), interval (Minimum/Maximum), number of patients $(\mathrm{n})$ or percentage (\%)

* Student $t$ test for independent samples

${ }^{* *}$ Qui-square test

this study is similar to ours, including cure rates for both groups and NNT.

Due to a rise of complication rates in the literature, FDA instructed surgeons to cautiously use PM for AVWP (20). Complications were categorized and classified according to ICS/IUGA (10).
In the present study there were only minor complications with no life risk of any patients. During the peroperatory period it was observed 8 patients $(18 \%)$ of the Mesh group with prepubic hematoma secondary to the needle passage that did not required surgical intervention and that resolved spontaneously. It was observed urinary retention 
Table 2 - POP-Q measurements in centimeters \pm standard deviation (SD) at pre- and postoperatory periods from Mesh and Control groups

\begin{tabular}{lccr}
\hline & Mesh & Control & $p^{\mathrm{a}}$ \\
\hline Aa & & & \\
& & & \\
Pre-op & $1.47(1.61)$ & $1.38(1.78)$ & 0.81 \\
Post-op & $-2.39(0.82)$ & $-1.59(1.01)$ & $<0.0001$ \\
$p^{\text {b }}$ & $<0.0001$ & $<0.0001$ &
\end{tabular}

Ba

Pre-op

Post-op

$p^{b}$

C

Pre-op

Post-op

$p^{b}$

D

Pre-op

Post-op

$p^{b}$

Ap

Pre-op

Post-op

$p^{b}$

Bp

Pre-op

Post-op

$p^{b}$
$3.38(2.50)$

$-2.46(0.70)$

$<0.0001$

-1.44 (5.10)

$-6.44(1.14)$

$<0.0001$

$2.55(2.50)$

0.10

$-1.57(1.04)$

$<0.0001$

$<0.0001$

$-1.56(4.90)$

0.90

$-6.70(1.34)$

0.32

$<0.0001$

$-2.78(5.54)$

$-3.80(4.89)$

0.36

$-7.6(0.66)$

$-7.8(1.30)$

0.84

$0.0006^{c}$

$<0.0001$

$-0.58(1.87)$

$-2.74(0.66)$

$<0.0001$

$<0.0001$

$\begin{array}{ll}-0.67(1.97) & 0.81\end{array}$

$\begin{array}{ll}-2.67(1.34) & 0.74\end{array}$

$0.42(3.33)$

$0.18(2.90)$

0.70

$-2.74(0.66)$

$-2.79(0.53)$

0.69

$<0.0001$ 
continuation

\section{GH (genital hiatus)}

$\begin{array}{lccc}\text { Pre-op } & 4.70(1.10) & 4.80(1.30) & 0.65 \\ \text { Post-op } & 2.63(0.69) & 2.76(0.64) & 0.34 \\ p^{b} & <0.0001 & <0.0001\end{array}$

\section{PB (perineal body)}

$\begin{array}{lccc}\text { Pre-op } & 2.70(0.84) & 2.70(0.77) & 0.71 \\ \text { Post-op } & 4.00(0.62) & 4.04(0.77) & 0.80 \\ \mathrm{p}^{\mathrm{b}} & <0.0001 & <0.0001\end{array}$

TVL (total vaginal length)

$\begin{array}{lccc}\text { Pre-op } & 9.35(1.04) & 9.40(1.03) & 0.81 \\ \text { Post-op } & 8.23(0.87) & 8.69(1.47) & 0.08 \\ p^{b} & <0.0001 & <0.0001\end{array}$

POP-Q = Pelvic Organ Prolapse Quantification

${ }^{\text {a }}$ Student $t$ test for independent samples

b Student $t$ test for paired samples

${ }^{\circ}$ Student $t$ test for paired samples (analysis of patients with point $D$ after the surgery)

Table 3 - Cure rates according POP stage (POP-Q). Results presented in frequency and percentage.

\begin{tabular}{lccc}
\hline POP stage & Mesh $(\mathrm{n}=43)$ & Control $(\mathrm{n}=53)$ & $\mathrm{p}^{*}$ \\
\hline $0-$ I* $^{* *}$ & $36(83.7 \%)$ & $30(55.5 \%)$ & 0.006 \\
II & $7(16.3 \%)$ & $24(44.5 \%)$ & \\
III & - & - & \\
IV & - & $53(100 \%)$ & \\
\hline TOTAL & $43(100 \%)$ & \multicolumn{3}{c}{} \\
\hline
\end{tabular}

* Student t-test for independent samples

** Objective cure of POP was defined as Stage POP-Q $<$ II after 12-month follow-up. 
Table 4 - VSS and QoL scores (ICIQ-VS) at the pre- and postoperatory periods from Mesh and Control groups. Values presented as mean \pm standard deviation (SD).

\begin{tabular}{lccc}
\hline & Mesh & Control & $\mathrm{p}^{\mathrm{a}}$ \\
\hline VSS (interval 0-53) & & & \\
Preop & $25.05(9.5)$ & $23.6(10.4)$ & 0.47 \\
Postop & $3.24(4.7)$ & $4.02(4.4)$ & 0.40 \\
$\mathrm{p}^{\mathrm{b}}$ & $<0.0001$ & $<0.0001$ & \\
QoL (interval 0-10) & & & 0.91 \\
Preop & $8.51(2.32)$ & $8.45(2.56)$ & 0.03 \\
Postop & $0.14(0.67)$ & $1.13(2.9)$ & \\
$\mathrm{p}^{\mathrm{b}}$ & $<0.0001$ & $<0.0001$ & \\
\hline
\end{tabular}

VSS $=$ Vaginal Score Symptoms

QoL $=$ Quality of Life score

a t Student test for independent samples

b t Student test for paired samples

Table 5 - Concurrent surgical procedures in Mesh $(n=45)$ and Control $(n=55)$ groups. Values represent the number of patients according to the type of surgery in each group and respective percentage.

\begin{tabular}{lccc}
\hline Concurrent surgical procedures & $\begin{array}{c}\text { MESH } \\
\mathrm{n}(\%)\end{array}$ & $\begin{array}{c}\text { CONTROL } \\
\mathrm{n}(\%)\end{array}$ & $\mathrm{p}^{*}$ \\
\hline Posterior colporraphy & $17(37.8)$ & $22(40)$ & 0.98 \\
Vaginal hysterectomy & $17(37.8)$ & $24(43.6)$ & 0.69 \\
Retropubic synthetic sling & - & $14(25.5)$ & - \\
\hline
\end{tabular}

* Student $t$ test for independent samples

during the first postoperatory period secondary to an infravesical obstruction due to the synthetic sling (control group) or due to the prepubic arms of the NAZCA TC. In three cases of the Mesh group (6.3\%) and two cases of the Control group (3.7\%) it was necessary to readjust the suburethral mesh, promoting its relaxation in the first day of postoperatory with complete resolution of the obstructive symptoms. After 12-month follow-up it was observed mesh exposition $<1 \mathrm{~cm}$ diameter on the anterior vaginal wall in four patients (9.3\%). Three patients were treated with a topic estrogen cream and sexual abstinence with good results. Only one patient $(2.3 \%)$ was submitted to partial resection of the exposed mesh and primary suture of the vaginal margins. These data are in accordance to the literature, that range from 5 to $15 \%(17,19,21,22)$.

The main limit of the present study was that it was performed in a single center and did not have an independent examiner during objective evaluations at the postoperatory period. Another point to be discussed is the randomization technique. Although a different number of women were assigned to each group, it did not alter the homogeneity of groups regarding sociodemographic, clinical and gynecological variables (POP-Q), allowing correct comparison of both groups (13). 97\% of patients were evaluated at 12-month follow-up signaling low rate of patient 
Table 6 - Safety according to the reported complication rates and to the standardized codes of the International Continence Society and International Urogynecology Association at intra, peri and postoperatory periods after 12-month follow-up of Mesh $(M)(n=43)$ and Control (C) $(n=54)$ groups.

\begin{tabular}{|c|c|c|c|c|c|c|c|}
\hline \multirow{2}{*}{ COMPLICATIONS } & \multicolumn{2}{|c|}{$\begin{array}{l}\text { Intra and periopera- } \\
\text { tory follow-up }\end{array}$} & \multicolumn{2}{|c|}{$\begin{array}{l}\text { Two-month follow- } \\
\text {-up }\end{array}$} & \multicolumn{2}{|c|}{ 12-month follow-up } & \multirow{2}{*}{$\begin{array}{l}\text { ICS / IUGA Code } \\
\text { (M) }\end{array}$} \\
\hline & $\begin{array}{c}M \\
n(\%)\end{array}$ & $\begin{array}{c}\mathrm{C} \\
\mathrm{n}(\%)\end{array}$ & $\begin{array}{c}M \\
n(\%)\end{array}$ & $\begin{array}{c}\mathrm{C} \\
\mathrm{n}(\%)\end{array}$ & $\underset{n(\%)}{M}$ & $\begin{array}{c}C \\
n(\%)\end{array}$ & \\
\hline $\begin{array}{l}\text { Bleeding } \\
(<500 \mathrm{~mL})\end{array}$ & $\begin{array}{c}1 \\
(2.3)\end{array}$ & $\begin{array}{c}1 \\
(1.8)\end{array}$ & - & - & - & - & 7AT1S1 \\
\hline Prepubic hematoma & $\begin{array}{c}8 \\
(18.6)\end{array}$ & - & - & - & - & - & 7AT1S1 \\
\hline Slight inguinal pain & - & - & $\begin{array}{c}5 \\
(11.6)\end{array}$ & - & - & - & $6 \mathrm{BT} 2 \mathrm{~S} 1$ \\
\hline $\begin{array}{l}\text { Urinary retention with relaxation of } \\
\text { the suburethral PM }\end{array}$ & $\begin{array}{c}3 \\
(7)\end{array}$ & $\begin{array}{c}2 \\
(3.7)\end{array}$ & - & - & - & - & 4BT1S1 \\
\hline $\begin{array}{l}\text { Mesh exposition in the anterior } \\
\text { vaginal wall }\end{array}$ & - & - & - & - & $\begin{array}{c}4 \\
(9.3)\end{array}$ & - & 2BT3S1 \\
\hline Dispareunia & - & - & - & - & $\begin{array}{c}1 \\
(2.3)\end{array}$ & - & 1BT3S1 \\
\hline
\end{tabular}

ICS = International Continence Society

IUGA = International Urogynecology Association

loss. This was one of the most significant aspects of the present study along with its design.

Finally, some authors advocate that the use of PM through the vaginal route is associated with low complication and POP recurrence rates. Nevertheless, after clarification, surgeons should help patients to decide on whether she takes the risk of some complications - such as mesh exposition - or face the risk of probable POP recurrence in the future (23).

\section{CONCLUSIONS}

The treatment of AVWP significantly improved the Ba point in the Mesh group in comparison to the Control group. There were no differences of the vaginal symptoms and QoL impact between the two groups after 12 months. There were few and low grade complications on both groups.

\section{ABBREVIATIONS}

POP = Pelvic organ prolapse

AVWP = Anterior vaginal wall prolapse

$\mathrm{PM}=$ Polypropylene mesh

SUI $=$ Stress urinary incontinence

POP-Q = Pelvic Organ Prolapse Quantification

ICS = International Continence Society

IUGA = International Urogynecology Association

$\mathrm{BMI}=$ Body mass index

ICIQ-VS = International Consultation on Incontinence Questionnaire - Vaginal Symptoms

VSS $=$ Vaginal symptoms score

SSS $=$ Sexual symptoms score 
QoL $=$ Quality of life

$\mathrm{M}=$ Mesh group

$\mathrm{C}=$ Control group

$\mathrm{SD}=$ Standard deviation

FDA = Food and Drug Administration

ARR $=$ Absolute risk reduction

NNT $=$ Number needed to treat

\section{ACKNOWLEDGMENTS}

The authors would like to thank the dedication and work of the nurse staff and the technical group of employees of the Ambulatory of Urogynecology of Jau. In special, the authors would like to thank Luzia Lucatto, Maria Aparecida Martinez, Rosely Spirandeo Peres, Sandra Maria de Camargo Junqueira and Silvana Aparecida Ronchi.

\section{CONFLICT OF INTEREST}

None declared.

\section{REFERENCES}

1. Lousquy R, Costa P, Delmas V, Haab F: Update on the epidemiology of genital prolapse. Prog Urol. 2009; 19: 907-15.

2. Tamanini JT, Lebrão ML, Duarte YA, Santos JL, Laurenti R: Analysis of the prevalence of and factors associated with urinary incontinence among elderly people in the Municipality of SãoPaulo, Brazil: SABE Study (Health, Wellbeing and Aging). Cad Saude Publica. 2009; 25: 1756-62.

3. Samuelsson EC, Victor FT, Tibblin G, Svärdsudd KF: Signs of genital prolapse in a Swedish population of women 20 to 59 years of age and possible related factors. Am J Obstet Gynecol. 1999; 180: 299-305.

4. Olsen AL, Smith VJ, Bergstrom JO, Colling JC, Clark AL: Epidemiology of surgically managed pelvic organ prolapse and urinary incontinence. Obstet Gynecol. 1997; 89: 501-6.

5. Rodrigues AM, de Oliveira LM, Martins K de F, Del Roy CA, Sartori MG, Girão MJ, et al.: Risk factors for genital prolapse in a Brazilian population. Rev Bras Ginecol Obstet. 2009; 31: 17-21.

6. Maher C, Baessler K: Surgical management of anterior vaginal wall prolapse: an evidencebased literature review. Int Urogynecol J Pelvic Floor Dysfunct. 2006; 17: 195-201.
7. Bump RC, Mattiasson A, Bø K, Brubaker LP, DeLancey JO, Klarskov $P$, et al.: The standardization of terminology of female pelvic organ prolapse and pelvic floor dysfunction. Am J Obstet Gynecol. 1996; 175: 10-7.

8. Haylen BT, de Ridder D, Freeman RM, Swift SE, Berghmans $B$, Lee J, et al.: An International Urogynecological Association (IUGA)/International Continence Society (ICS) joint report on the terminology for female pelvic floor dysfunction. Neurourol Urodyn. 2010; 29: 4-20.

9. Tamanini JT, Almeida FG, Girotti ME, Riccetto CL, Palma PC, Rios LA: The Portuguese validation of the International Consultation on Incontinence Questionnaire-Vaginal Symptoms (ICIQ-VS) forBrazilian women with pelvic organ prolapse. Int Urogynecol J Pelvic Floor Dysfunct. 2008; 19: 1385-91.

10. Haylen BT, Freeman RM, Lee J, Swift SE, Cosson M, Deprest J, et al.: An International Urogynecological Association (IUGA)/ International Continence Society (ICS) joint terminology andclassification of the complications related to native tissue female pelvic floor surgery. Int Urogynecol J. 2012; 23: 515-26.

11. Palma P, Riccetto C, Prudente A, Dalphorno F, Delroy C, Castro $R$, et al.: Monoprosthesis for anterior vaginal prolapse and stress urinary incontinence: midterm results of an internationalmulticentre prospective study. Int Urogynecol J. 2011; 22: 1535-41.

12. Feldner PC Jr, Castro RA, Cipolotti LA, Delroy CA, Sartori MG, Girão MJ: Anterior vaginal wall prolapse: a randomized controlled trial of SIS graft versus traditional colporrhaphy. Int Urogynecol J. 2010; 21: 1057-63.

13. Suresh K: An overview of randomization techniques: An unbiased assessment of outcome in clinical research. J Hum Reprod Sci. 2011; 4: 8-11.

14. Zhu L, Lang J, Sun Z, Ren C, Liu X, Li B: Pelvic reconstruction with mesh for advanced pelvic organ prolapse: a new economic surgical method. Menopause. 2011; 18: 328-32.

15. Nicita G: A new operation for genitourinary prolapse. J Urol. 1998; 160: 741-5.

16. Debodinance P, Amblard J, Fatton B, Cosson M, Jacquetin B: The prosthetic kits in the prolapse surgery: is it a gadget ?. J Gynecol Obstet Biol Reprod (Paris). 2007; 36: 267-75.

17. Maher CM, Feiner B, Baessler K, Glazener CM: Surgical management of pelvic organ prolapse in women: the updated summary version Cochrane review. Int Urogynecol J. 2011; 22: 1445-57.

18. Nguyen JN, Burchette RJ: Outcome after anterior vaginal prolapse repair: a randomized controlled trial. Obstet Gynecol. 2008; 111: 891-8.

19. Delroy CA, de A Castro R, Dias MM, Feldner PC Jr, Bortolini MA, Girão MJ, et al.: The use of transvaginal synthetic mesh for anterior vaginal wall prolapse repair: a randomized controlled trial. Int Urogynecol J. 2013; 30. [Epub ahead of print] 
20. U.S. Food and Drug Administration. FDA Safety Communication: UPDATE on Serious Complications Associated with Transvaginal Placement of Surgical Mesh for Pelvic Organ Prolapse. Available at: http://www.fda.gov/MedicalDevices/Safety/AlertsandNotices/ ucm262435.htm. Last access: October 30, 2012.

21. Altman D, Väyrynen T, Engh ME, Axelsen S, Falconer C; Nordic Transvaginal Mesh Group. Anterior colporrhaphy versus transvaginal mesh for pelvic-organ prolapse. N Engl J Med. 2011; 364: 1826-36. Erratum in: N Engl J Med. 2013; 368: 394.
22. Sokol Al, Iglesia CB, Kudish BI, Gutman RE, Shveiky D, Bercik $\mathrm{R}$, et al.: One-year objective and functional outcomes of a randomized clinical trial of vaginal mesh for prolapse. Am J Obstet Gynecol. 2012; 206: 86.e1-9.

23. Krlin RM, Murphy AM, Goldman HB: Pro: the contemporary use of transvaginal mesh in surgery for pelvic organ prolapse. Curr Opin Urol. 2012; 22: 282-6.

Correspondence address: Dr. José Tadeu Nunes Tamanini Departamento de Medicina / Universidade Federal de São Carlos - UFSCar Rodovia Washington Luís, km 235 - SP-310 São Carlos, SP, 13565-905, Brazil E-mail: tadeutamanini@ufscar.br 